\title{
Risk factors for advanced duodenal and ampullary adenomatosis in familial adenomatous polyposis: a prospective, single-center study $\square$
}

\section{(๑) $\odot \ominus$}

\author{
Authors \\ M. Sulbaran' ${ }^{1}$, F. G. Campos ${ }^{2}$, U. Ribeiro Jr. ${ }^{2}$, H. S. Kishi ${ }^{3}$, P. Sakai ${ }^{1}$, E. G. H. de Moura ${ }^{1}$, L. Bustamante-López ${ }^{2}$, \\ M. Tomitão ${ }^{3}$, S. C. Nahas' ${ }^{2}$, I. Cecconello², A. V. Safatle-Ribeiro ${ }^{1}$
}

Institutions

1 Gastrointestinal Endoscopy Service, Gastroenterology Department, Clinics Hospital, University of Sao Paulo School of Medicine, Sao Paulo, Brazil

2 Surgical Division, Gastroenterology Department, Clinics Hospital, University of Sao Paulo School of Medicine, Sao Paulo, Brazil

3 Pathology Department, Clinics Hospital, University of Sao Paulo School of Medicine, Sao Paulo, Brazil

submitted 16.3.2017

accepted after revision 18.12.2017

Bibliography

DOI https://doi.org/10.1055/a-0577-2650 |

Endoscopy International Open 2018; 06: E531-E540

(c) Georg Thieme Verlag KG Stuttgart · New York

ISSN 2364-3722

Corresponding author

Marianny Sulbaran, MD MSc, Gastrointestinal Endoscopy

Service, Gastroenterology Department, Clinics Hospital, University of Sao Paulo School of Medicine, Av. Dr. Eneas de Carvalho Aguiar, 255 - Block 3 - Cerqueira Cesar, Sao Paulo - SP, 01246-000, Brazil

Fax: +55-11-31494790

mariannysulbaran@gmail.com

\section{ABSTRACT}

Background and study aims To determine the clinical features associated with advanced duodenal and ampullary adenomas in familial adenomatous polyposis. Secondarily, we describe the prevalence and clinical significance of jejunal polyposis.

Patients and methods This is a single center, prospective study of 62 patients with familial adenomatous polyposis. Duodenal polyposis was classified according to Spigelman and ampullary adenomas were identified. Patients with Spigelman III and IV duodenal polyposis underwent balloon assisted enteroscopy. Predefined groups according to Spigelman and presence or not of ampullary adenomas were related to the clinical variables: gender, age, family history of familial adenomatous polyposis, type of colorectal surgery, and type of colorectal polyposis.

Results Advanced duodenal polyposis was present in 13 patients ( $21 \%$; 9 male) at a mean age of $37.61 \pm 13.9$ years. There was a statistically significant association between family history of the disease and groups according to Spigelman $(P=0.03)$. Seven unrelated patients ( 6 male) presented ampullary adenomas at a mean age of $36.14 \pm 14.2$ years. The association between ampullary adenomas and extraintestinal manifestations was statistically significant in multivariate analysis $(P=0.009)$. Five endoscopic types of non-ampullary adenoma were identified, showing that lesions larger than $10 \mathrm{~mm}$ or with a central depression presented foci of high grade dysplasia. Among 28 patients in 12 different families, a similar Spigelman score was identified; $10 / 12$ patients $(83.3 \%)$ who underwent enteroscopy presented small tubular adenomas with low grade dysplasia in the proximal jejunum.

Conclusions Advanced duodenal polyposis phenotype may be predictable from disease severity in a first-degree relative. Ampullary adenomas were independently associated with the presence of extraintestinal manifestations.

Study registration: NCT02656134

\section{Introduction}

Prophylactic colectomy has provided a breakthrough in the management of familial adenomatous polyposis (FAP) [1-3]. Adequate colorectal polyposis control has changed the natural history of the disease, improving the prognosis and life expec- tancy of affected patients [1]. Within this context, periampullary carcinoma is the leading mortality etiology among patients with FAP who have undergone prophylactic colectomy [4-7]. Therefore, a clear understanding of small-bowel adenomatosis in FAP seems mandatory. 
Efforts have been made to identify the clinical factors associated with the development of advanced duodenal disease and an increased risk for duodenal and ampullary adenocarcinoma. However, results from different study groups have been inconsistent [ 8 -10]. The only endoscopic feature that has been associated with the presence of foci of high grade dysplasia and a subsequent higher risk for duodenal adenocarcinoma is size of adenomas larger than $10 \mathrm{~mm}[8,10]$.

Thus, the aim of this study was to establish the clinical risk factors and endoscopic features associated with the development of ampullary and advanced duodenal polyposis in a Brazilian population with FAP. Additionally, we aimed to describe the prevalence and clinical impact of jejunal adenomatosis in these patients.

\section{Patients and methods}

This is a prospective, single referral center study, undertaken between July 2013 and April 2016. The protocol was approved by University of Sao Paulo School of Medicine Ethics Committee and registered at Clinical Trials (NCT02656134).

\section{Patients}

A cohort of 64 patients with clinical and/or endoscopic diagnosis of FAP met the inclusion criteria for the study. Patients were routinely treated in the Colorectal Surgery Division at the University of Sao Paulo Medical School according to standard international surveillance intervals. Two patients refused to participate and so a total of 62 patients in 46 different families were enrolled in the study. Endoscopic examinations were performed at the Gastrointestinal Endoscopy Unit, Clinics Hospital, University of Sao Paulo School of Medicine. All patients gave their informed consent before inclusion in the study. Patients who had undergone previous duodenectomy/gastroduodenopancreatectomy, pregnant women, and patients with severe comorbidities were excluded from the study.

\section{Data collection}

Clinical data were collected aided by electronic chart records and personal interviews with patients. Age, gender, family history for FAP, colonic polyposis phenotype: classic or attenuated based on the colonic count reported at colonoscopy and surgical report (attenuated phenotype was classified, based on the number, distribution of polyps, age of onset of the disease, and the presence of at least one first-degree relative with the disease), presence of extraintestinal manifestations, type of colorectal surgical reconstruction technique: total proctocolectomy with ileal pouch or total colectomy with ileorectal anastomosis, and diagnosis of colorectal cancer data were recorded.

\section{Prospective endoscopic and histologic evaluation}

Patients were prepared with a 6-hour fast and administration of $10 \mathrm{~mL}$ simeticone solution. Esophagogastroduodenoscopies (EGD) were performed under conscious sedation with fentanyl, midazolam, and propofol administered by a second physician. All patients were evaluated with lateral (Olympus, TJF-Q180V) and forward view (Olympus, GIF-H180) EGD. Endoscopic features, number, size, anatomic location, and Paris classification were reported for every case. Duodenal polyposis was classified according to the Spigelman staging system and ampullary adenomas were also identified. A minimum of four biopsies were taken from larger duodenal polyps and two biopsies from suspicious ampullary lesions. All histopathologic specimens were reviewed by an experienced pathologist with expertise in gastrointestinal tract evaluation. Additionally, when endoscopic mucosectomies were performed, the resected specimens were used to complement the Spigelman staging of duodenal adenomatosis. Patients with advanced duodenal polyposis (Spigelman III or IV) underwent antegrade balloon assisted endoscopy (BAE) (Fuji, EN-450T5 or Fuji, EN-580 T) for jejunal examination approximately 1 month after initial EGD. All gastroduodenoscopies and BAEs were performed by two experienced endoscopists (M.S. and A. S.R).

\section{Data analysis}

Non-ampullary duodenal adenomatosis was stratified into two groups according to Spigelman stages: group 1 included Spigelman stages 0 , I, and II; group 2 was represented by patients classified as Spigelman stages III and IV.

According to the presence or absence of ampullary adenomas, patients were also stratified into two groups.

Clinical variables: age, gender, family history for FAP, colonic polyposis type, presence of extraintestinal manifestations, and type of colorectal surgical reconstruction technique were related to stratified groups for non-ampullary duodenal adenomatosis and ampullary polyposis.

Continuous data were analyzed using the Student's $t$ test and categorical variables by Fisher-exact test or Chi-squared test, aided by the Statistical Package for the Social Sciences software version 20.0, with level of significance of $5 \%$. For statistically significant variables, multivariate analysis using logistic regression was performed.

\section{Results}

A total of 62 patients from 46 different families were studied, with a mean age of $36.1 \pm 14.2$ years; 32 (51.6\%) were female ( $\triangleright$ Table1). Regarding the 16 cases with extraintestinal manifestations, there were five cases of desmoid tumors, four sebaceous cysts, two mandibular osteomas, two adrenal tumors, two thyroid tumors, and one case of hypophysis tumor, solid pseudopapillary neoplasm of the pancreas, and congenital hypertrophy of the retinal pigment epithelium (CHRPE). Three patients presented chronic abdominal pain related to compression of related organs by desmoid tumors and 59 patients were asymptomatic. Among the 62 patients, 52 (84\%) had already undergone colorectal surgical treatment. Of those, 44 (84.6\%) underwent prophylactic colectomy, and 8 (15.4\%) patients had undergone surgical treatment for colorectal cancer. Of those 8 patients, 6 curative and 2 palliative surgeries were performed. 
- Table 1 Clinical variables related to FAP patient groups classified according to Spigelman.

\begin{tabular}{|c|c|c|c|c|c|c|}
\hline \multirow[b]{2}{*}{ Variable } & \multicolumn{4}{|c|}{ Spigelman stage } & \multirow[b]{2}{*}{$\begin{array}{l}\text { Total } \\
\text { n (\%) }\end{array}$} & \multirow[b]{2}{*}{$P$ value } \\
\hline & \multicolumn{2}{|c|}{$\begin{array}{l}0, \text { I, II } \\
n(\%) \\
n=49(79 \%)\end{array}$} & \multicolumn{2}{|c|}{$\begin{array}{l}\text { III and IV } \\
n(\%) \\
n=13(21 \%)\end{array}$} & & \\
\hline Age, mean $\pm S D$, years & \multicolumn{2}{|c|}{$35.75 \pm 14.4$} & \multicolumn{2}{|c|}{$37.61 \pm 13.9$} & $36.14 \pm 14.2$ & $0.999^{1}$ \\
\hline Sex & & & & & & $0.083^{2}$ \\
\hline - Male & 21 & $(42.9)$ & 9 & $(69.2)$ & $30(48.4)$ & \\
\hline - Female & 28 & $(57.1)$ & 4 & $(30.8)$ & $32(51.6)$ & \\
\hline Family history & & & & & & $0.030^{2}$ \\
\hline - Yes & 46 & (93.9) & 9 & $(69.2)$ & $55(88.7)$ & \\
\hline - No & 3 & $(6.1)$ & 4 & $(30.8)$ & $7(11.3)$ & \\
\hline Colonic polyposis & & & & & & $0.183^{2}$ \\
\hline - Classic & 40 & $(81.6)$ & 13 & $(100)$ & $53(85.5)$ & \\
\hline - Attenuated & 9 & $(18.4)$ & 0 & $(0)$ & $9(14.5)$ & \\
\hline Extraintestinal manifestations & & & & & & $0.445^{2}$ \\
\hline - Yes & 12 & $(24.5)$ & 4 & $(30.8)$ & $16(25.8)$ & \\
\hline - No & 37 & $(75.5)$ & 9 & $(69.2)$ & $46(74.2)$ & \\
\hline Colorectal surgery & & & & & & $0.638^{2}$ \\
\hline - Ileal pouch & 26 & $(63.4)$ & 7 & $(63.6)$ & $33(63.5)$ & \\
\hline - IRA & 15 & $(36.6)$ & 4 & $(36.4)$ & $19(36.5)$ & \\
\hline Colorectal cancer & & & & & & $0.347^{2}$ \\
\hline - Yes & 5 & $(10.2)$ & 3 & $(23.1)$ & $8(12.9)$ & \\
\hline - No & 44 & $(89.8)$ & 10 & $(76.9)$ & $54(87.1)$ & \\
\hline Ampullary adenoma & & & & & & $0.153^{2}$ \\
\hline - Yes & 4 & $(8.2)$ & 3 & $(23.1)$ & $7(11.3)$ & \\
\hline - No & 45 & $(91.8)$ & 10 & (76.9) & $55(88.7)$ & \\
\hline
\end{tabular}

- Table 2 Logistic regression of family history with groups according to Spigelman.

\begin{tabular}{|l|c|c|c|c|}
\hline Parameter & OR & 95\%Cl & P value \\
\hline No family history & 1.00 & & & \\
\hline Positive family history & 0.15 & 0.03 & 0.77 & $\mathbf{0 . 0 2 3}$ \\
\hline
\end{tabular}

\section{Prevalence of duodenal adenomatosis and association with clinical variables}

The prevalence of duodenal adenomatosis and advanced duodenal polyposis was $59.7 \%$ and $20.9 \%$, respectively and the distribution of patients according to Spigelman stages can be seen in $>$ Table 1. When the association between Spigelman groups and clinical variables was evaluated, the only variable with statistical significance was positive family history for FAP, showing that $93.9 \%$ of patients in Spigelman group 0 - II had a positive family history for FAP, in contrast to $69.2 \%$ of patients with a positive family history in the advanced duodenal adenomatosis group $(P=0.030)$ ( $>$ Table 1 ). According to logistic regression modeling, patients with a positive FAP family history had a 6.67 times lower risk of presenting advanced duodenal disease $(P=0.023)$ ( $>$ Table 2$)$. There were no clinical variables associated with the development of Spigelman III and IV advanced duodenal polyposis ( $\triangleright$ Table 1 ). 
- Table 3 Familial distribution of Spigelman stages among different relatives from each family.

\begin{tabular}{|c|l|l|l|}
\hline Family & $\begin{array}{l}\text { No. of } \\
\text { patients }\end{array}$ & $\begin{array}{l}\text { Spigelman } \\
\text { stage }\end{array}$ & $\begin{array}{l}\text { Consanguinity } \\
\text { degree }\end{array}$ \\
\hline 1 & 2 & IV, IV & $1^{\circ}$ \\
\hline 2 & 2 & IV, IV & $1^{\circ}$ \\
\hline 3 & 3 & II, II, 0 & $1^{\circ}$ \\
\hline 4 & 3 & I, 0, 0 & $1^{\circ}$ \\
\hline 5 & 2 & 0,0 & $1^{\circ}$ \\
\hline 6 & 2 & II, 0 & $1^{\circ}$ \\
\hline 7 & 2 & II, II & $2^{\circ}$ \\
\hline 8 & 2 & 0,0 & $1^{\circ}$ \\
\hline 9 & 4 & II, II, I, 0 & $1^{\circ}$ \\
\hline 10 & 2 & III, II & $1^{\circ}$ \\
\hline 11 & 2 & III, II & $1^{\circ}$ \\
\hline 12 & 2 & 0,0 & $1^{\circ}$ \\
\hline
\end{tabular}

\section{Familial distribution of Spigelman stages}

Familial distribution of Spigelman stages among the relatives from each family was analyzed when at least two family members were included in the study. Within the total group, 28 patients belonged to 12 different families. Four patients in two different families presented advanced duodenal disease, Spigelman IV. A total of 20 relatives from eight different families were consistently classified as Spigelman score 0 to II, and four patients from two other families were staged as Spigelman II or
III, suggesting a familial segregation pattern for duodenal disease severity in first-degree relatives ( $\triangleright$ Table 3 ).

\section{Endoscopic features of non-ampullary lesions}

Systematic observation of non-ampullary duodenal lesions facilitated the identification of different endoscopic types of lesion that presented specific histological association patterns ( $>$ Table 4).

In total, 37 patients classified as Spigelman I, II, III, or IV presented small $(<10 \mathrm{~mm})$ flat elevated whitish lesions that corresponded to tubular adenomas with low grade dysplasia (Lesion type 1a) ( $\triangleright$ Fig. 1); 13 patients classified as Spigelman III or IV presented advanced adenomas (Lesion types 1b, 2a, 2b, and 3) (> Figs.2-5, > Video 1). Different morphologic patterns with specific histologic associations for advanced adenomas were identified, as shown in $>$ Table 4.

\section{Ampullary adenomas}

Seven cases (six male and one female) of ampullary adenoma were identified at a mean age of $36.6 \pm 16.7$ years. Of these, 6 were classified as minor and 1 major adenoma (>10 mm) ( $\triangleright$ Fig.6). All patients with ampullary adenomas were from different families. Three patients were Spigelman III, three were Spigelman II, and the patient with major ampullary adenoma presented no polyps in the duodenum. All ampullary lesions corresponded to tubular adenomas with low grade dysplasia.

When the group of patients with ampullary adenomas was related to clinical variables, the presence of extraintestinal manifestations $(P=0.009)$ and colorectal cancer $(P=0.039)$ was statistically significant ( $\triangleright$ Table 5 ). In multivariate analysis, the only variable that showed an independent association with statistical significance was the presence of extraintestinal manifestations $(P=0.037)$ ( $\triangleright$ Table 6$)$. According to logistic regres-

- Table4 Endoscopic features of non-ampullary duodenal lesions.

\begin{tabular}{|c|c|c|c|c|c|c|}
\hline $\begin{array}{l}\text { Lesion } \\
\text { type }\end{array}$ & $\begin{array}{l}\text { Endoscopic } \\
\text { features of lesions }\end{array}$ & $\begin{array}{l}\text { Anatomic localiza- } \\
\text { tion ordered by } \\
\text { frequency in the } \\
\text { duodenum }\end{array}$ & $\begin{array}{l}\text { Paris endo- } \\
\text { scopic classifi- } \\
\text { cation }\end{array}$ & $\begin{array}{l}\text { No. of } \\
\text { patients (\%) }\end{array}$ & $\begin{array}{l}\text { Spigelman } \\
\text { stage }\end{array}$ & Histology \\
\hline $1 a$ & $\begin{array}{l}\text { Flat elevated whitish } \\
\text { lesions, <10 mm }\end{array}$ & $\begin{array}{l}\text { 2nd, 3rd portion and } \\
\text { bulb }\end{array}$ & $0-11 a$ & $37 / 62(59.7 \%)$ & I, II, III, IV & $\begin{array}{l}\text { Tubular adenomas with } \\
\text { low grade dysplasia }\end{array}$ \\
\hline $1 b$ & $\begin{array}{l}\text { Flat elevated whitish } \\
\text { lesions, > } 10 \mathrm{~mm}\end{array}$ & $\begin{array}{l}\text { 2nd, 3rd portion and } \\
\text { bulb }\end{array}$ & $0-11 a$ & $7 / 13(53.8 \%)$ & III, IV & $\begin{array}{l}\text { Tubular or tubulovillous } \\
\text { adenomas with low } \\
\text { grade dysplasia }\end{array}$ \\
\hline $2 a$ & $\begin{array}{l}\text { Flat elevated whitish } \\
\text { lesions, with reddish } \\
\text { central depression, } \\
3-10 \mathrm{~mm}\end{array}$ & 2nd and $3 r d$ portion & $0-\|l a+\| c$ & $4 / 13(30.8 \%)$ & III, IV & $\begin{array}{l}\text { Tubular or tubulovillous } \\
\text { adenomas with low } \\
\text { grade dysplasia, tubular } \\
\text { adenomas with high } \\
\text { grade dysplasia }\end{array}$ \\
\hline $2 b$ & $\begin{array}{l}\text { Flat elevated whitish } \\
\text { lesions, with reddish } \\
\text { central depression, } \\
10-50 \text { mm }\end{array}$ & 2nd portion and bulb & $0-\|l a+\| c$ & $3 / 13(23.1 \%)$ & III, IV & $\begin{array}{l}\text { Tubulovillous adenomas } \\
\text { with low or high grade } \\
\text { dysplasia }\end{array}$ \\
\hline 3 & $\begin{array}{l}\text { Sessile polypoid le- } \\
\text { sions, } 10-40 \mathrm{~mm}\end{array}$ & 2nd portion and bulb & $0-$ Is & $1 / 13(7.7 \%)$ & IV & $\begin{array}{l}\text { Tubulovillous adenomas } \\
\text { with high grade dysplasia }\end{array}$ \\
\hline
\end{tabular}




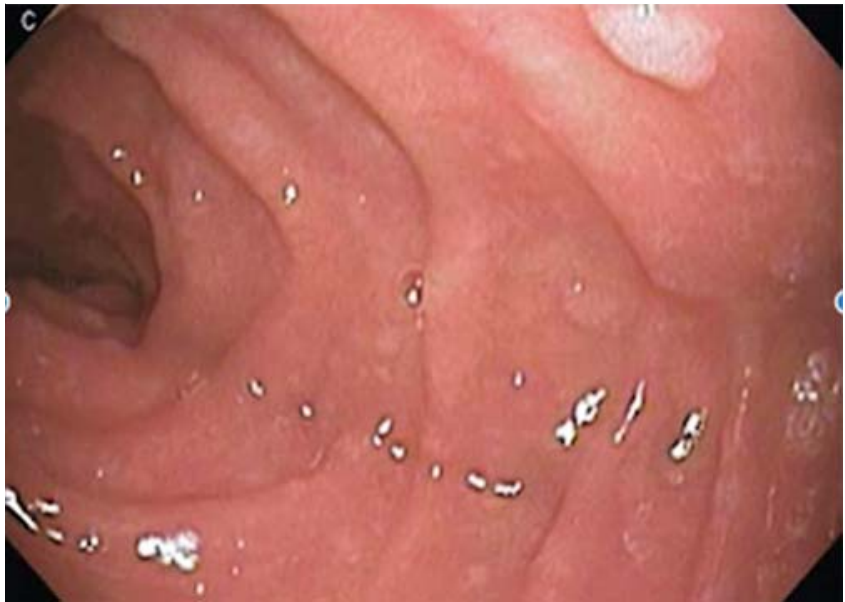

- Fig. 1 Lesion type 1a: Endoscopic image of flat elevated whitish lesions $<10 \mathrm{~mm}$, located in second duodenal portion of a 35-yearold male patient, Spigelman II.

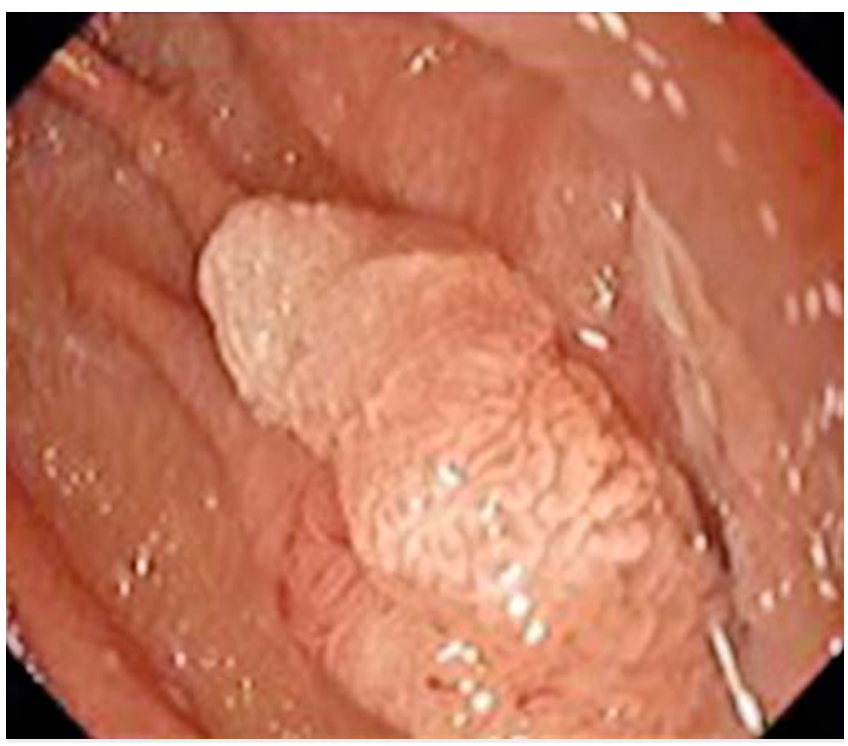

- Fig. 2 Lesion type 1b: Endoscopic image of flat elevated whitish lesion $>10 \mathrm{~mm}$, located in third duodenal portion of a 33-year-old male patient, Spigelman IV.

sion analysis, patients with extraintestinal manifestations have a 7.18 times higher risk of presenting ampullary adenoma $(\triangleright$ Table 6).

\section{Jejunal polyposis}

In total, 12 patients with Spigelman III/IV underwent BAE with a minimum insertion length of $100 \mathrm{~cm}$ distal to the Treitz ligament. Of these $10(83.3 \%)$ patients presented small $(<10 \mathrm{~mm})$ flat elevated, whitish lesions located in the proximal jejunum, which corresponded to tubular adenomas with low grade dysplasia. Two patients had no jejunal lesions.

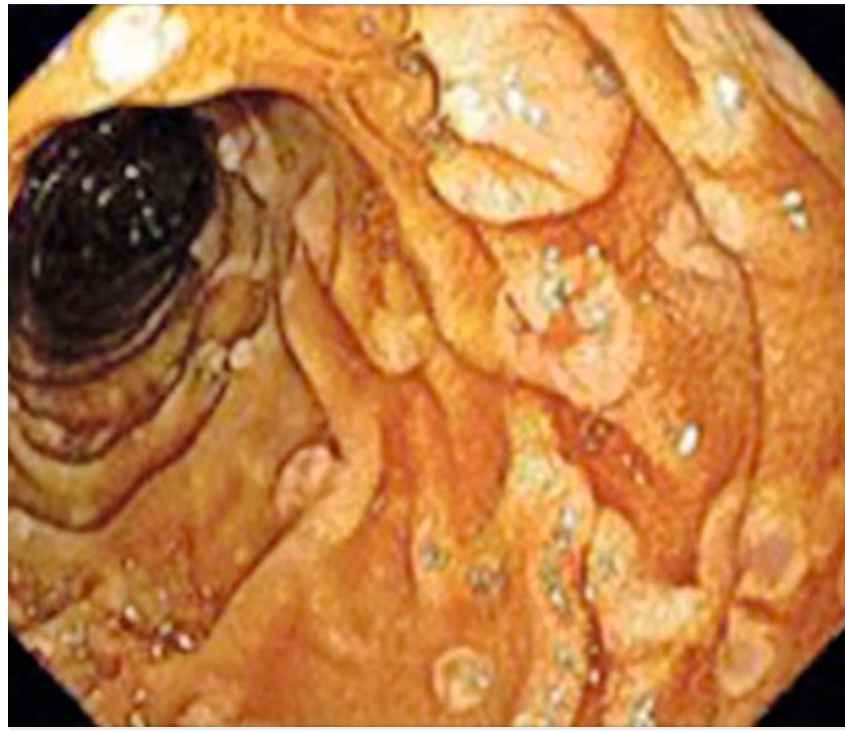

- Fig. 3 Lesion type 2a. Endoscopic image of lesions with central depression $<10 \mathrm{~mm}$ in second duodenal portion of a 23-year-old male patient, Spigelman III.

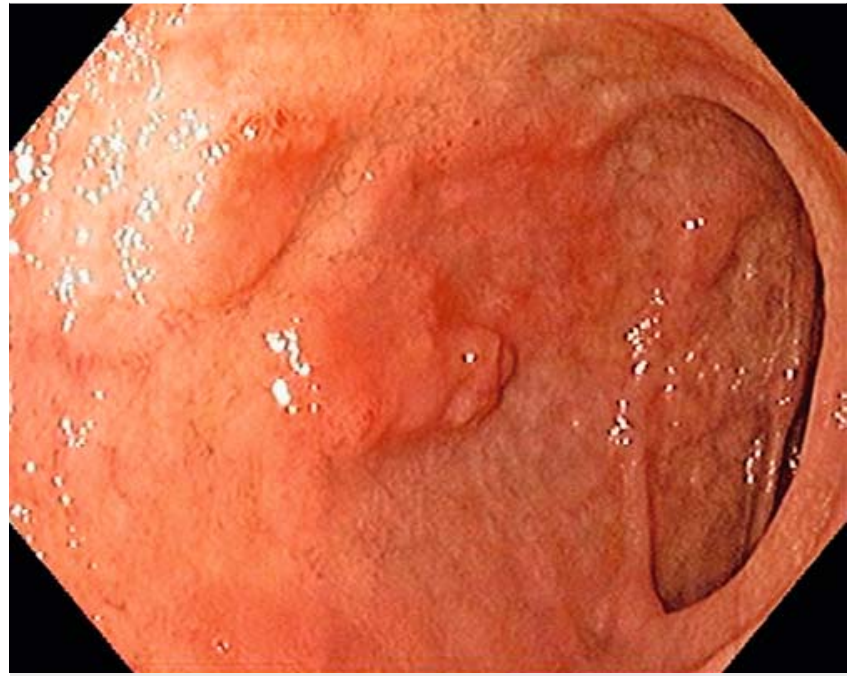

- Fig. 4 Lesion type 2b: Endoscopic image of flat elevated adenoma with central depression of approximately $20 \mathrm{~mm}$ size, located in duodenal bulb of a 55-year-old female patient, Spigelman IV.

\section{Discussion}

The data presented in this study represent a large prospective series of patients with FAP and with an important proportion of individuals already submitted to colectomy in a single university tertiary hospital in Latin America. Our results indicate that a positive family history of FAP was a protective factor against advanced duodenal disease. The interpretation of this result may have several explanations. Relatives from index cases may have incorporated sooner in the intestinal polyposis registry. Consequently, this group of patients may have received a closer follow-up since an earlier stage of the disease, which may have resulted in a more favorable duodenal polyposis 


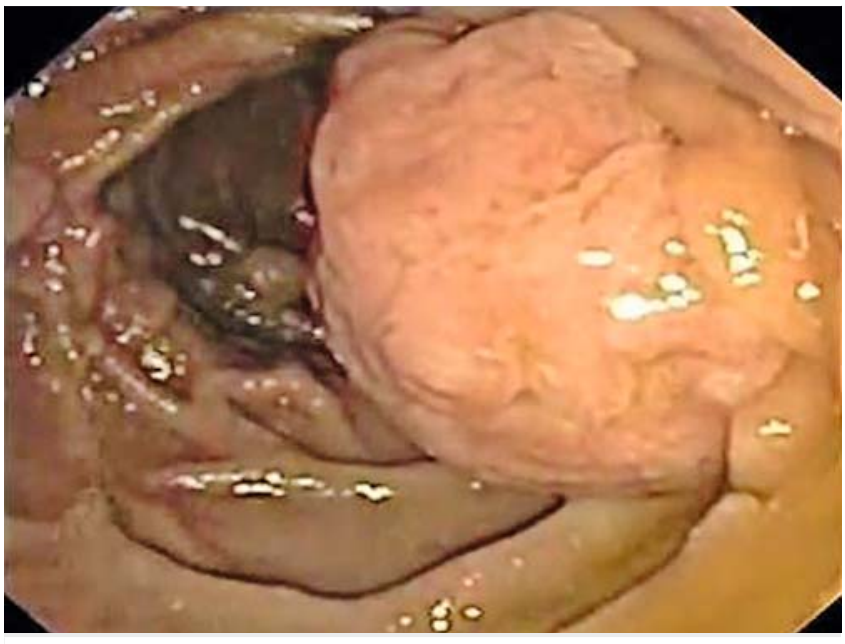

- Fig. 5 Lesion type 3: Endoscopic image of a polypoid lesion, approximately $30 \mathrm{~mm}$ size, located in second duodenal portion of a 27-year-old male patient, Spigelman IV.

prognosis. On the other hand, advanced cases of duodenal polyposis showing a negative family history may be the result of a different genetic background. De novo germline mutations are present in $25 \%$ of cases of FAP $[11,12]$. These mutations have been shown to correlate with a delay in diagnosis and a more severe colorectal phenotype [13]. Perhaps spontaneous mutations could be responsible for a more severe duodenal phenotype as well. Our study is based on phenotype characterization of duodenojejunal disease. This approach may also have its own strengths and pitfalls. Although we can suggest that it is possible that the presence of spontaneous mutations in patients with a negative family history for the disease may have a role for conditioning a more aggressive duodenal phenotype, we can only confirm this with further characterization of the genetic background of this population. These results are not comparable to other studies that intended to identify risk factors for advanced duodenal disease, mainly because a positive family history for the disease was not one of the factors analyzed by those authors $[9,10,14]$. On the other hand, the actual limitation of a wide genetic analysis at the present time encouraged a more profound clinical analysis of the factors that could be implicated in the development of advanced duodenal disease.

Familial distribution of Spigelman score among relatives from each family suggested a familial segregation pattern of duodenal disease. Although the small number of patients with at least one more relative included in the study may limit further statistical analysis of this observation, familial clustering of duodenal/ampullary cancer has previously been reported $[14,15]$. A larger study that included 144 patients in 74 families was able to demonstrate that the occurrence and severity of periampullary neoplasia in FAP patients segregates in families [15]. The next step that should be taken in this analysis would be characterization of the molecular background of these patients, in order to determine whether this pattern is the result of a genetic etiology or an environmental effect. Of note, a fa-

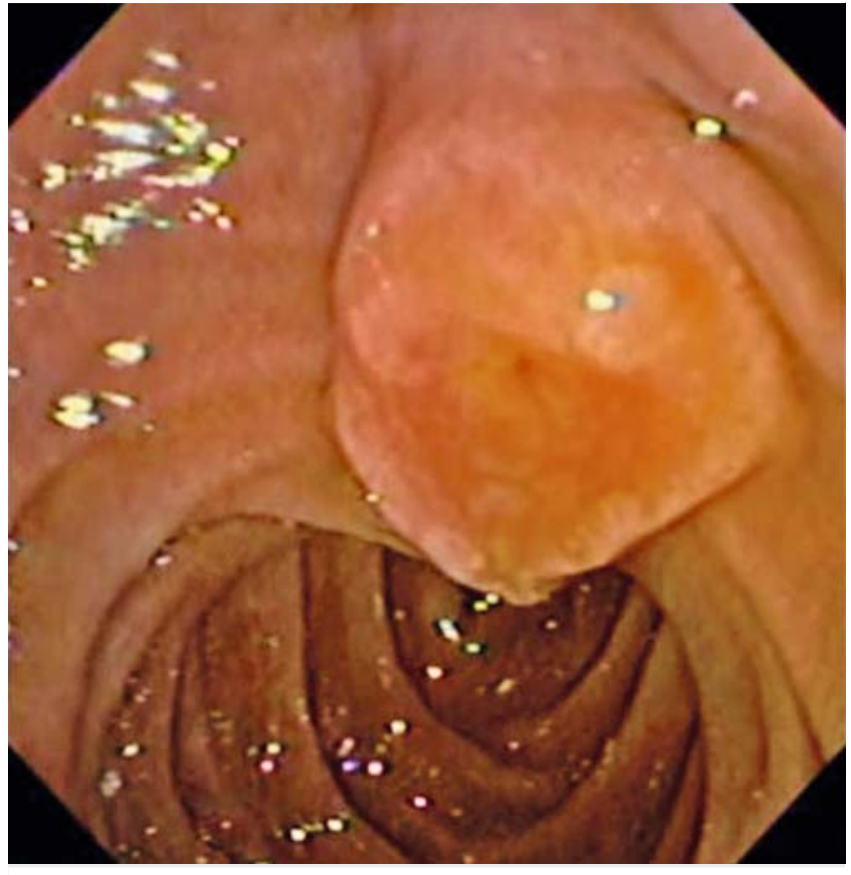

- Fig. 6 Endoscopic image of a major ampullary adenoma with low grade dysplasia in a 19-year-old male patient, Spigelman 0.

milial clustering for ampullary adenomas was not observed in the patients enrolled in this study. However, the hypothesis of familial clustering for this entity cannot be rejected because patients who presented with ampullary adenomas in the present study did not have sufficient relatives included in order to make a further analysis on this subject.

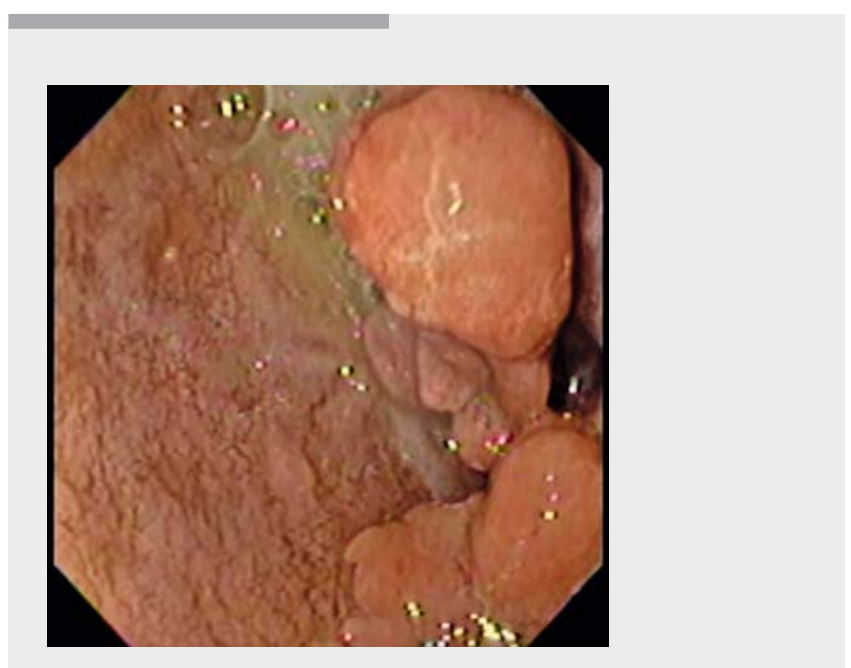

$\checkmark$ Video 1 Endoscopic examination of a 27-year-old male patient, classified as Spigelman IV, showing advanced adenomas (lesion type 3) and a scar from previous endoscopic mucosal resection at the duodenal bulb. As the scope is advanced to the second duodenal portion, the coexistence of different types of lesion (types 1a, 1b, 2a, 2b, and 3) can be seen, with a major duodenal papilla with adequate bile drainage. 
- Table 5 Clinical variables related to presence or absence of ampullary adenomas in patients with FAP.

\begin{tabular}{|c|c|c|c|c|c|c|}
\hline \multirow[b]{2}{*}{ Variable } & \multicolumn{4}{|c|}{ Ampullary adenomas } & \multirow[b]{2}{*}{ Total } & \multirow[b]{2}{*}{$P$ value } \\
\hline & \multicolumn{2}{|c|}{$\begin{array}{l}\text { Yes } \\
\text { n (\%) }\end{array}$} & \multicolumn{2}{|c|}{$\begin{array}{l}\text { No } \\
\text { n (\%) }\end{array}$} & & \\
\hline Age, mean $\pm S D$, years & \multicolumn{2}{|c|}{$36.6 \pm 16.70$} & \multicolumn{2}{|c|}{$36.09 \pm 14.05$} & $36.14 \pm 14.2$ & $0.999^{1}$ \\
\hline Sex & & & & & & $0.066^{2}$ \\
\hline - Male & 6 & $(85.7)$ & 24 & $(43.6)$ & $30(48.4)$ & \\
\hline - Female & 1 & $(14.3)$ & 31 & $(56.4)$ & $32(51.6)$ & \\
\hline Family history & & & & & & $0.174^{2}$ \\
\hline - Yes & 5 & $(71.4)$ & 50 & $(90.9)$ & $55(88.7)$ & \\
\hline - No & 2 & $(28.6)$ & 5 & $(9.1)$ & $7(11.3)$ & \\
\hline Colonic polyposis & & & & & & $0.579^{2}$ \\
\hline - Classic & 7 & $(100)$ & 47 & $(85.4)$ & $54(87.1)$ & \\
\hline - Attenuated & 0 & $(0)$ & 8 & $(14.6)$ & $8(12.9)$ & \\
\hline Extraintestinal manifestations & & & & & & $0.009^{2}$ \\
\hline - Yes & 5 & $(71.4)$ & 11 & $(20)$ & $16(25.8)$ & \\
\hline - No & 2 & $(28.6)$ & 44 & $(80)$ & $46(74.2)$ & \\
\hline Colorectal surgery & & & & & & $0.507^{2}$ \\
\hline - Ileal pouch & 4 & $(57.1)$ & 29 & $(64.4)$ & $33(63.5)$ & \\
\hline - IRA & 3 & $(42.9)$ & 16 & $(35.6)$ & $19(36.5)$ & \\
\hline Colectomy & & & & & & $0.039^{2}$ \\
\hline - Yes & 3 & $(42.9)$ & 5 & $(9.1)$ & $8(12.9)$ & \\
\hline - No & 4 & $(57.1)$ & 50 & (90.9) & $54(87.1)$ & \\
\hline Spigelman groups & & & & & & $0.153^{2}$ \\
\hline - $0, \mathrm{I}, \mathrm{II}$ & 4 & $(57.1)$ & 45 & $(81.8)$ & $49(79.0)$ & \\
\hline - III, IV & 3 & $(42.9)$ & 10 & $(18.2)$ & $13(21.0)$ & \\
\hline
\end{tabular}

- Table 6 Logistic regression of extraintestinal manifestations and colorectal cancer related to presence of ampullary adenomas.

\begin{tabular}{|l|c|c|c|}
\hline Parameter & OR & $\mathbf{9 5} \% \mathbf{C l}$ & P value \\
\hline No extraintestinal manifestations & 1.00 & & 45.9 \\
\hline Presence of extraintestinal manifestations & 7.18 & 1.1 & 0.037 \\
\hline No colorectal cancer & 1.00 & & 27.0 \\
\hline Presence of colorectal cancer & 3.91 & 0.6 & 0.166 \\
\hline
\end{tabular}

A previous study that retrospectively analyzed 41 consecutive patients with FAP concluded that advanced age and mutations in the central part of the APC gene (codons 279-1309) were risk factors for advanced duodenojejunal disease [9]. Two years later, in a prospective study with 48-month follow-up in 58 patients with FAP who had a high initial Spigelman score
(>7 points), the same group demonstrated that neither age nor mutation site were risk factors for the development of high grade dysplasia [10]. Taking into consideration that the old classification of dysplasia gave a lowering of the Spigelman score and stage by -1.33 points and -0.70 stages [16], whereas the modified Spigelman score according to Vienna classifica- 
tion updates [17] gives 3 points for the presence of foci of high grade dysplasia and 1 point for low grade dysplasia [10], it is likely and logical to believe that an initial Spigelman score of > 7 points could be a risk factor for high grade dysplasia development.

The only endoscopic feature that has been associated with the presence of high grade dysplasia, even using high-resolution endoscopy or narrow band imaging (NBI), is adenoma size larger than $10 \mathrm{~mm}[8,10]$. Additionally, studies that have incorporated the use of chromoendoscopy for duodenal evaluation in patients with FAP have shown a higher number of identified polyps. Nevertheless, the higher number of lesions identified has not been demonstrated to correlate with a significant clinical impact $[18,19]$. Based on these facts, chromoendoscopy was not used routinely in the present study, instead it was applied in selected cases to improve the detailed examination of specific lesions. In the present study, we were able to recognize five different endoscopic patterns of duodenal lesions present in patients with FAP. Four of these correspond to lesions commonly described as advanced adenomas (Lesion types 1b, 2a, $2 b$, and 3 ). We believe that this characterization is important in order to produce a risk stratification for the development of high grade dysplasia among these lesions, as each endoscopic pattern showed a specific histological association. Interestingly, lesions with a central depression presented foci of high grade dysplasia, even when their size was less than $10 \mathrm{~mm}$, suggesting that this endoscopic feature could be predictive of higher risk for advanced duodenal disease. Moreover, when we compare each lesion pattern of size less than $10 \mathrm{~mm}$ with one with similar morphologic features but size larger than $10 \mathrm{~mm}$, we observe more aggressive histologic characteristics. This observation suggests that we might be looking at a specific endoscopic pattern at different stages of evolution. Although it would be interesting to validate this observation prospectively in a larger population, the risk of leaving advanced adenomas in place would probably outweigh the benefits of confirming this observation.

Additionally, the role of emerging technologies such as dual focus $\mathrm{NBI}$ and probe-based confocal laser endomicroscopy (pCLE) for characterization of duodenal lesions should be analyzed. Although these diagnostic modalities have demonstrated a high (90\%) negative predictive value (NPV) with respect to standard histology, further characterization of different histologic architecture has not been validated [20]. Taking into consideration that one of the major current limitations of actual duodenal surveillance in FAP would be to overlook dysplastic lesions that may evolve to cancer during the recommended surveillance interval [21], it does not seem useful to introduce a high cost technology such as PCLE in order to overcome this limitation. In contrast, the routine use of high-resolution endoscopy in specialized centers could contribute to a better standard endoscopic examination that facilitates an accurate characterization of duodenal polyps and Spigelman score.

Regarding localization of duodenal adenomas, it has been classically described that most dysplastic adenomas in FAP are located in the second and third duodenal portion [22]. In the present study, the duodenal bulb was also a frequent location for advanced adenomas. Although the ideal endoscopic screening protocol has not been prospectively validated [21], this fact reinforces the observation that both axial and lateral view EGD should be performed in order to have a clear view of all segments of the duodenum to optimize its endoscopic evaluation and yield a more precise Spigelman score for each patient [19, 21].

Duodenal adenomatosis evaluation in FAP at the present time has its own limitations. Although the worldwide adopted staging system, the Spigelman classification, has never been studied prospectively, it has been shown to correlate with the risk of duodenal malignancy. Stages II, III, and IV disease are associated with a $2.3 \%, 2.4 \%$, and $36 \%$ risk of duodenal cancer, respectively [23]. Some considerations should be made when interpreting this association. Understaging of duodenal polyposis based on endoscopic biopsies can occur and has previously been reported $[1,24]$. In our study, we report a case initially staged as Spigelman III based on endoscopic biopsies. After analyzing the mucosectomy specimen of advanced adenoma, we reclassified that patient as Spigelman IV. Taking into consideration the wide gap in estimated duodenal cancer risk between a Spigelman III and IV, we can say that every time a patient is substaged as Spigelman III, that patient's risk for duodenal cancer is being 15 times underestimated. Whenever a high index of suspicion of substaging occurs, a very close follow-up should be taken to further establish the best therapeutic approach for these patients.

When analyzing the clinical factors associated with ampullary adenomas, we have shown that the only factor independently related to the presence of ampullary adenomas was extraintestinal manifestations. Based on the fact that the presence of ampullary adenomas itself is an extracolonic manifestation of the disease, it might be logical to presuppose this association. Nevertheless, the same association was not found for non-ampullary duodenal adenomas. The fact that ampullary adenomas were found in patients with different Spigelman stages confirms that ampullary and non-ampullary duodenal disease should be treated as different biological entities [14]. Moreover, the presence of extraintestinal manifestations should raise the clinical suspicion for ampullary adenomas as these factors presented an independent association. Regarding the possibility of random ampullary biopsies as protocol, we chose not to perform biopsies in endoscopically normal ampulla. The presence of altered histology of the ampulla in random biopsies has been described [25]. However, biopsies of the ampulla carry a small associated risk of pancreatitis. Additionally, ampullary adenomas in FAP have a slow progression, with evidence that development of ampullary cancer is higher in polyps larger than $1 \mathrm{~cm}$ [14], which were not found in the present study. We believe that the risks of collecting biopsies in endoscopically normal ampulla outweigh the benefits of diagnosing an adenoma that will take years to progress into clinically significant disease with criteria for resection.

It has been demonstrated that the severity of duodenal polyposis is a clear predictor for detecting adenomas distal to the Treitz ligament [26-28]. Taking this concept into consideration, BAE was performed in patients with Spigelman score III or 
IV. The prevalence of jejunal polyposis was high $(83.3 \%)$ in these patients. However, it was represented by lesions that were not clinically significant, similar to what has already been described in previous studies [26]. In this context, we suggest that indications for BAE should be individualized in patients with Spigelman score III or IV who may need further study of the extent of jejunal involvement as potential surgery candidates. Regarding the method for enteroscopic evaluation, BAE was chosen because of the possibility of histological confirmation and therapeutic interventions if necessary [29]. Although capsule endoscopy has been demonstrated to be useful and safe for the surveillance of jejunal-ileal polyps in patients with FAP [27], it may underestimate the number of polyps and miss the detection of large lesions [30].

We acknowledge several limitations of the study. A genetic analysis should take place in order to further understand and characterize the molecular background that could predispose patients to a more severe duodenal phenotype. FAP is a rare genetic disease and this limited the number of patients included in this study. Moreover, the distribution of advanced duodenal disease led to a small number of patients with Spigelman score III and IV for analysis. This limited the statistical analysis of important clinical observations such as the association between specific endoscopic patterns and histopathology. It would be useful to set up multicenter studies that could overcome this drawback.

In summary, the severity of duodenal adenomatosis may be predicted from the severity of the duodenal phenotype in a first-degree relative. Adenomas larger than $10 \mathrm{~mm}$ or with central depression may contain foci of high grade dysplasia with an increased risk for developing advanced duodenal neoplasia. Extraintestinal manifestations should raise the clinical suspicion for ampullary adenomas as these factors present an independent association.

\section{Acknowledgements}

The authors acknowledge the talented nurses and staff at the Gastrointestinal Endoscopy Unit, Clinics Hospital of the University of Sao Paulo, for their valuable work and contribution to this study.

\section{Competing interests}

None

\section{References}

[1] Drini M, Speer A, Dow C et al. Management of duodenal adenomatosis in FAP: single centre experience. Fam Cancer 2012; 11: 167-173

[2] Jaganmohan S, Lynch PM, Raju RP et al. Endoscopic management of duodenal adenomas in familial adenomatous polyposis - a singlecenter experience. Dig Dis Sci 2012; 57: 732 - 737

[3] Jagelman DG, DeCosse JJ, Bussey HJ. Upper gastrointestinal cancer in familial adenomatous polyposis. Lancet 1988; 1: 1149-1151
[4] Arvanitis ML, Jagelman DG, Fazio VW et al. Mortality in patients with familial adenomatous polyposis. Dis Colon Rectum 1990; 33: 639 642

[5] de Campos FG, Perez RO, Imperiale AR et al. Evaluating causes of death in familial adenomatous polyposis. J Gastrointest Surg 2010; 14: $1943-1949$

[6] Vasen HF, Möslein G, Alonso A et al. Guidelines for the clinical management of familial adenomatous polyposis (FAP). Gut 2008; 57: $704-713$

[7] Campos FG, Sulbaran M, Safatle-Ribeiro AV et al. Duodenal adenoma surveillance in patients with familial adenomatous polyposis. World J Gastrointest Endosc 2015; 7: 950 - 959

[8] Lopez-Ceron M, van den Broek FJ, Mathus-Vliegen EM et al. The role of high-resolution endoscopy and narrow-band imaging in the evaluation of upper GI neoplasia in familial adenomatous polyposis. Gastrointest Endosc 2013; 77: 542 - 550

[9] Saurin JC, Ligneau B, Ponchon T et al. The influence of mutation site and age on the severity of duodenal polyposis in patients with familial adenomatous polyposis. Gastrointest Endosc 2002; 55: 342 - 347

[10] Saurin JC, Gutknecht C, Napoleon B et al. Surveillance of duodenal adenomas in familial adenomatous polyposis reveals high cumulative risk of advanced disease. J Clin Oncol 2004; 22: 493-498

[11] Balmaña J, Balaguer F, Cervantes A et al. Familial risk-colorectal cancer: ESMO Clinical Practice Guidelines. Ann Oncol 2013; 24: vi73 - 80

[12] Bisgaard ML, Fenger K, Bülow S et al. Familial adenomatous polyposis (FAP): frequency, penetrance, and mutation rate. Hum Mutat 1994; 3 : $121-125$

[13] Rustin RB, Jagelman DG, McGannon E et al. Spontaneous mutation in familial adenomatous polyposis. Dis Colon Rectum 1990; 33: 52 - 55

[14] Latchford AR, Neale KF, Spigelman AD et al. Features of duodenal cancer in patients with familial adenomatous polyposis. Clin Gastroenterol Hepatol 2009; 7: 659-663

[15] Sanabria JR, Croxford R, Berk TC et al. Familial segregation in the occurrence and severity of periampullary neoplasms in familial adenomatous polyposis. Am J Surg 1996; 171: 136 - 140; discussion 140131

[16] Mathus-Vliegen EM, Ruys AT, Alderlieste YA et al. Response to jejunal cancer in patients with familial adenomatous polyposis. Clin Gastroenterol Hepatol 2011; 9: 279-280

[17] Schlemper RJ, Riddell RH, Kato $Y$ et al. The Vienna classification of gastrointestinal epithelial neoplasia. Gut 2000; 47: 251 -255

[18] Picasso M, Filiberti R, Blanchi S et al. The role of chromoendoscopy in the surveillance of the duodenum of patients with familial adenomatous polyposis. Dig Dis Sci 2007; 52: 1906-1909

[19] Dekker E, Boparai KS, Poley JW et al. High resolution endoscopy and the additional value of chromoendoscopy in the evaluation of duodenal adenomatosis in patients with familial adenomatous polyposis. Endoscopy 2009; 41: 666-669

[20] Pittayanon R, Rerknimitr R, Imraporn B et al. Diagnostic values of dua focus narrow band imaging and probe-based confocal laser endomicroscopy in FAP-related duodenal adenoma. Endosc Int Open 2015; 3 : $\mathrm{E} 450$ - E455

[21] Saurin JC, Pioche M, Rivory J. Surveillance of duodenal adenomas in familial adenomatous polyposis patients: medical objectives and technical requirements. Endosc Int Open 2015; 3: E456-E457

[22] Spigelman AD, Williams CB, Talbot IC et al. Upper gastrointestinal cancer in patients with familial adenomatous polyposis. Lancet 1989; 2: $783-785$

[23] Groves C], Saunders BP, Spigelman AD et al. Duodenal cancer in patients with familial adenomatous polyposis (FAP): results of a 10 year prospective study. Gut 2002; 50: 636-641

[24] de Vos tot Nederveen Cappel WH, Järvinen HJ, Björk J et al. Worldwide survey among polyposis registries of surgical management of severe 
duodenal adenomatosis in familial adenomatous polyposis. Br J Surg 2003; 90: 705-710

[25] Church JM, McGannon E, Hull-Boiner S et al. Gastroduodenal polyps in patients with familial adenomatous polyposis. Dis Colon Rectum 1992; 35: $1170-1173$

[26] Alderlieste YA, Rauws EA, Mathus-Vliegen EM et al. Prospective enteroscopic evaluation of jejunal polyposis in patients with familial adenomatous polyposis and advanced duodenal polyposis. Fam Cancer 2013; 12: $51-56$

[27] laquinto G, Fornasarig M, Quaia M et al. Capsule endoscopy is useful and safe for small-bowel surveillance in familial adenomatous polyposis. Gastrointest Endosc 2008; 67: 61-67
[28] Mönkemüller K, Fry LC, Ebert M et al. Feasibility of double-balloon enteroscopy-assisted chromoendoscopy of the small bowel in patients with familial adenomatous polyposis. Endoscopy 2007; 39: 52 57

[29] Sulbaran M, de Moura E, Bernardo W et al. Overtube-assisted enteroscopy and capsule endoscopy for the diagnosis of small-bowel polyps and tumors: a systematic review and meta-analysis. Endosc Int Open 2016; 4: E151-E163

[30] Wong RF, Tuteja AK, Haslem DS et al. Video capsule endoscopy compared with standard endoscopy for the evaluation of small-bowel polyps in persons with familial adenomatous polyposis (with video). Gastrointest Endosc 2006; 64: 530-537 